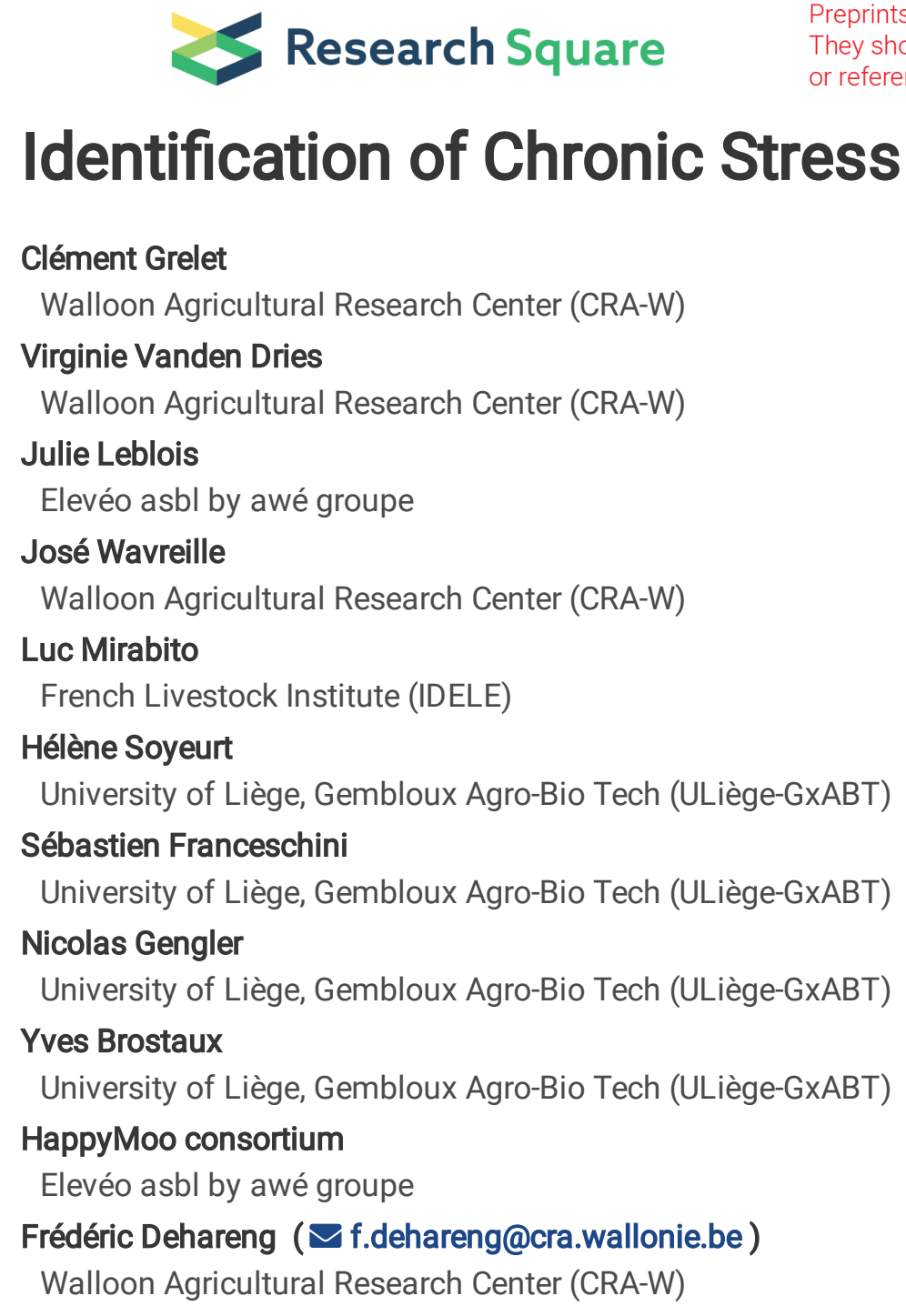

\author{
Clément Grelet \\ Walloon Agricultural Research Center (CRA-W) \\ Virginie Vanden Dries \\ Walloon Agricultural Research Center (CRA-W) \\ Julie Leblois \\ Elevéo asbl by awé groupe \\ José Wavreille \\ Walloon Agricultural Research Center (CRA-W) \\ Luc Mirabito \\ French Livestock Institute (IDELE) \\ Hélène Soyeurt \\ University of Liège, Gembloux Agro-Bio Tech (ULiège-GxABT) \\ Sébastien Franceschini \\ University of Liège, Gembloux Agro-Bio Tech (ULiège-GxABT) \\ Nicolas Gengler \\ University of Liège, Gembloux Agro-Bio Tech (ULiège-GxABT) \\ Yves Brostaux \\ University of Liège, Gembloux Agro-Bio Tech (ULiège-GxABT) \\ Elevéo asbl by awé groupe \\ Frédéric Dehareng ( $\nabla$ f.dehareng@cra.wallonie.be ) \\ Walloon Agricultural Research Center (CRA-W)
}

HappyMoo consortium

\title{
Identification of Chronic Stress Biomarkers in Dairy Cows
}

\section{Research Article}

Keywords: dairy, cows, biomarkers, chronic stress, sources, duration, animals, milk production of cows, noise

Posted Date: June 3rd, 2021

DOI: https://doi.org/10.21203/rs.3.rs-569271/v1

License: (c) (i) This work is licensed under a Creative Commons Attribution 4.0 International License. Read Full License 


\section{Abstract}

Stress in dairy herds can occur from multiple sources. When stress becomes chronic because of a long duration and inability of animals to adapt, it is likely to affect the emotional state, health, immunity, fertility and milk production of cows. While assessing chronic stress in herds would be beneficial, no real consensus has emerged from the literature regarding the indicators of interest. The goal of this study was to compare and evaluate potential biomarkers for chronic stress after inducing stress over a 4-week period through severe overstocking, restricted access to feed and punctual unusual events. A total of 30 cows were involved in the experiment and two similar groups were constituted. Over a 4-week period, the 15 cows of the stress group were housed in overstocked conditions, with $4.6 \mathrm{~m}^{2}$ per cow, including resting and feeding areas. In this area, only 7 individual places at the feeding area were available for the 15 cows to generate competition for feed access. Once weekly and during 2 hours, an additional stress was induced by moving cows to an unfamiliar barn and diffusion of stressing noises (dog barking). Meanwhile, the 15 cows of the control group stayed in the original barn, with more than $10 \mathrm{~m}^{2}$ per cow and more individual places at the feeding area than cow number. On a weekly basis, several variables considered as potential biomarkers for chronic stress were recorded. Collected data were analyzed using single trait linear repeated mixed models. No differences were observed regarding milk yield, bodyweight of cows or body condition score but the milk loss was more pronounced in the stress group. Whereas no differences were observed in terms of activity between the groups, the standard deviation of activity per cow per week was higher and the rumination of cows was lower in the stress group. The heart rate was lower in the stress group and showed more heterogeneity at the end of the stress period. No differences were observed regarding salivary cortisol, blood glucose, $\beta$-endorphin, thyroxine and leucocyte profile. A higher level of hair cortisol and blood fructosamine were observed in the stress group at the end of the stress period. Among the variables highlighted, milk losses and fructosamine were not specific biomarkers for stress while heart rate variables were difficult to collect in practice, consequently the hair cortisol content seemed to be the most promising indicator to assess chronic stress at a large scale.

\section{Introduction}

Assessing and improving welfare is an important issue in the dairy sector requiring appropriate phenotypes ${ }^{1}$. Among the various aspects related to welfare, the stress of animals is an important one. The first works on stress were led by Hans Selye under the concept of general adaptation syndrome in $1936^{2}$. It was first described as a typical syndrome, representing a common response to a damage, with symptoms being independent of the nature of the damaging agent. Selye specified later that stress was an interaction between non-specific damage and defense and that anything that endangers life causes stress and adaptive responses ${ }^{3}$, and comes with a definition that is still accepted nowadays: "stress is the non-specific response of the body to any demand made upon it" ${ }^{4}$. In such, stress is part of life and cannot be avoided. Stress can be perceived as a neutral or positive condition (eustress) or cause negative effects (distress), and reduce welfare when adaptation is not possible ${ }^{4}$. This general concept is differently considered following the discipline, e.g. in behavioral sciences stress is regarded as perception of threat, with resulting anxiety discomfort, emotional tension, and difficulty in adjustment, whereas in pure neuro-endocrinology stress defined as any stimulus inducing the release of adrenocorticotropic hormone (ACTH) and adrenal glucocorticoids ${ }^{5}$.

Since the first concept in 1936, the stress has been divided in 3 steps: alarm, resistance and exhaustion. In the first step, the body shows changes induced by the first exposure to stressor, enabling to fight or flee. When the stress continues, without possible adaptation, the alarm characteristics disappears and resistance develops, and finally, prolonged exposure may results in exhaustion and potentially death ${ }^{6}$. When the alarm step only is experienced, the stress is defined as acute or transitory. The acute stress occurs consequent to a short-lived situation, either physical, emotional or psychological, that generally - allows a quick and complete adaptation to recover of the physiological balance. Under these conditions, stress is often well tolerated despite the fact that it may induce important physiological variations ${ }^{7}$. In farm animals, it concerns the immediate biological responses to acute challenges (e.g., parturition, castration, weaning, mixing of animals from different

Page 2/22 
social groups, restraint, transportation, slaughter, heat and humidity) and follows a common pattern of response through the activation of the hypothalamic-pituitary-adrenocortical (HPA) axis and an increase in circulating cortisol levels in blood ${ }^{8}$.

Resistance and exhaustion comes when the stress is chronic -repeated or continuous on long term- with no possibility for the animal to adapt or control. In chronic stress, the autonomic nervous system rarely has a chance to activate the relaxation response, and the overexposure to stress hormones results in an exhaustion of the adaptation system, resulting in alteration of biological functions and associated negative effects ${ }^{7}$. However, many factors challenging animal welfare could become long lasting, moving stress from acute to chronic (e.g., chronic diseases, overstocking, permanent sources of pain and fear, inappropriate/aversive human handling or management, environmental noises and discomfort, competition, inadequate barn design, difficulties to access food, prolonged periods of high heat and humidity). Surprisingly, most of the physiological research on dairy cows welfare focused on acute stress, while chronic stress, which has a more pronounced effect on welfare and production, has received less attention ${ }^{9}$. Indeed, chronic stress affects immune, metabolic, endocrine and psychological status of cows ${ }^{7}$. This causes a higher susceptibility to metabolic, inflammatory and infectious diseases ${ }^{7,10,11}$. Chronic stress is also associated with fertility troubles ${ }^{12,13}$, shrinkage of thymus ${ }^{8}$, growth disturbances (Elsasser et al., 1995), weight loss ${ }^{8}$, and lower milk production ${ }^{14}$. Consequently, it has negative impact on production and economics of farms, but above all on welfare of cows and societal perception of dairy production.

Therefore, there is a strong interest to assess chronic stress in dairy farms. Frequent monitoring would allow detection of troubles and improvement of stress condition of cows, resulting in higher welfare for cows and revenues for farmers. It would also allow objective communication and labelling about the welfare of dairy cows towards consumers and citizens. For the large-scale assessment of chronic stress, relevant indicators, proxies or biomarkers are needed. Ideally, they should be reliable, easy to assess and measure, cheap, quantitative and objective. Physiological and biochemical indices seem to be more reliable, objective and easier to access than behavioral observations, unless those are automatically recorded, stored and processed. Biomarkers should be specific as well, as many traits (e.g., production, fertility, ingestion, body condition score, rumination) that might be potentially informative (i.e., affected by chronic stress) are also dependent upon many other factors (e.g., lactation stage, parity, social position, circadian cycles, feeding circumstances).

In the assessment of acute stress, the quantification of cortisol in blood plasma samples collected some minutes after the exposure to stress is considered as the gold standard ${ }^{8}$. However, plasma or salivary cortisol levels are not very informative to detect chronic stress situations ${ }^{8}$ as when the stress is maintained for some time, circulating levels of plasma cortisol return to baseline ${ }^{15,16}$. Specific biomarkers for chronic stress are needed, but no real consensus has emerged from the literature. Among the referenced potential biomarkers, the most promising seems to be the concentration of cortisol in hair. The exact mechanism by which cortisol is incorporated into hair is not yet fully understood ${ }^{17}$. During hair growth, cortisol is supposed to be continuously incorporated into the hair shaft through vascular supply ${ }^{18}$. Additionally, cortisol is likely to be incorporated into the hair from the surrounding tissues and possibly fluids, such as sweat and sebum or synthetized by the hair follicle itself $17,19,20$. However, hair cortisol is commonly assumed to be an indicator of long term HPA axis activation $8,21,22$. Therefore, hair cortisol could potentially be a useful marker to assess repeated or long term stress over the last weeks 20 and is not affected by short, single or scarce events ${ }^{23}$. Notably, hair cortisol content has been reported to be higher for cows with diseases or metabolic imbalance ${ }^{21,24,25}$, after castration ${ }^{26}$ or after repeated ACTH challenges ${ }^{27}$. Nonetheless, the potential of hair cortisol as a global chronic stress biomarker, e.g. reflecting chronic stress from psychological sources, is not well documented. Alternatively, in a review by Trevisi and Bertoni (2009), several other potential biomarkers were mentioned such as glycated protein (fructosamine), $\beta$-endorphin and modification of the immune profile through lymphocyte decrease, increase in the neutrophil/lymphocyte ratio, inhibition of proinflammatory cytokine production and reduction in peripheral mononuclear cells. By affecting the sensitivity of the HPA axis ${ }^{8}$, chronic stress could potentially affect the pituitary gland, the release of hormones such as thyroid-stimulating hormone and indirectly the thyroid hormones. The heart rate variability has also been referenced as a potential indicator of stress from physical, pathological and emotional origins ${ }^{7,9,28}$. Finally, behavioral observations such as the avoidance distance is also potentially reflecting chronic stress ${ }^{29,47}$. Majority of these 
potential indicators are poorly documented as biomarkers of chronic stress, or there is no consensus emerging to consider them as relevant biomarkers for general chronic stress. To our knowledge, no experiment has been carried out to induce chronic stress with the objective to assess and compare those potential biomarkers. In order to further perform large-scale chronic stress monitoring, the goal of this study is to compare and evaluate potential chronic stress biomarkers by inducing 4 weeks stress through severe overstocking, restricted access to feed and punctual unusual events.

\section{Materials And Methods}

\section{Ethical statement}

The experiment was carried out in accordance with the ARRIVE guidelines, the EU Directive 2010/63/EU for animal experiments and the protocol (19-2181) was approved by the ethical commission of Liège University. The sample size was calculated in order to use only the necessary number of cows. Among the biomarkers listed in the literature, the hair cortisol is the most frequently mentioned and was then used to calculate the sample size. Effect of stress on hair cortisol $\left(d=\left(\mu-\mu_{0}\right) / \sigma\right)$

was found $0.5^{24}$ or to be higher than $1^{30,31}$. Then an intermediate level of 0.75 was selected, and combined with an a risk of $5 \%$ and a test power $(1-\beta)$ of $80 \%$, to reach a minimum number of 12 cows per group. To prevent from potential removing of cows during the trial for ethical reasons 3 cows were added to each group to reach a number of 15 cows per group. The total number of animals being limited to 30 , the experiment was not replicated.

\section{Animals and induction of stress}

The data in this study were collected in the experimental herd of the Walloon Agricultural Research Centre (CRA-W, Gembloux, Belgium), from February to March 2020. A total of 30 cows were involved in the experiment: 25 Holstein and 5 Holstein $x$ Simmental crossbreed F1 cows. To avoid pathological or metabolic biases, the cows were selected regarding absence of diseases and with a lactation stage greater than 30 days in milk (DIM). The cows were divided into control and stress groups of 15 cows each. Groups were constituted to have similar mean and standard deviation regarding parity, milk yield, lactation stage, and equivalent proportion of pregnant, dominant and crossbred cows in both group. Parities were comprised between 1 and 6, with an average of 2, and DIM ranged from 43 to 400 , with an average of 168 . All cows were originally housed in a common straw-bedded free stall barn pen, with more than $10 \mathrm{~m}^{2}$ per cow and more individual places at the feedbunk than cow number. Then, for a period of 4 weeks, the 15 cows of the stress group were housed in overstocked condition, with 4.6 $\mathrm{m}^{2}$ per cow, including resting and feeding areas, by moving them into a smaller straw-bedded free stall pen of the same building. In this area, only 7 feed bunks were available to generate competition for feed access. Once weekly, for 2 hours, and additional stress was induced by moving cows to an unfamiliar barn and diffusion of stressing noises (dog barking). During the 4 weeks, the 15 cows of the control group stayed in the original barn, with more than $10 \mathrm{~m}^{2}$ per cow and more individual places at the feedbunk than cow number. The two pens for the stress and the control group were in the same barn, facing each other and only separated by the feeding area of $4 \mathrm{~m}$, with identical environment regarding exposure, temperature, materials, design or feeding times. Thus the pen effect was considered limited or non-existent. All cows received after the morning milking, approximately at 09h00, the same TMR diet composed by maize silage, grass silage and concentrate. The stress period finished at the end of the week 4, and all 30 cows were gathered into the original barn with more than $10 \mathrm{~m}^{2}$ per cow and more feedbunk places than cow number. Schematic representation of the experiment is presented in Fig. 1.

\section{General variables}

Milk yield was measured daily during the experiment. The milk yield dynamic evolution of individual cows was calculated as the daily percentage change compared to the average of week 0. Body condition score (BCS) were recorded by two trained observers using a five-point scale with quarters ${ }^{32}$ and cows were weighted weekly for stress group, and only at the beginning and at the end of the trial for the control group in order to avoid induction of stress. Clinical disease and oestrus were observed as well.

\section{Recording of behavior}


Activity and rumination were recorded continuously during all the experiment, with a time resolution of 2 hours, using the system SCR Heatime ® Pro (Allflex, Palmerston North, New Zealand). The avoidance distance test were realized following the Welfare Quality ${ }^{\circledR}$ protocol, weekly for the stress group, and only at the beginning and the end of the trial for the control group in order to avoid induction of stress. Once weekly, at the 6th day of each week as described in Fig. 1, all the 30 cows were observed during one hour, by two observers, at the rate 15 minutes per group of 15 cows, repeated four times by alternating observers. Observations took into account the interactions between animals such as given and received chasing, head butts and grooming. For further analysis, the social position of cows (i.e. dominant, neutral or dominated) was determined from the experience of the herd managers and updated after separation of the 2 groups using the difference between given and received aversive interactions observations (i.e. chasing and head-butts). The $30 \%$ cows with higher and positive differences were considered as dominant, the $30 \%$ cows with lower and negative differences were considered as dominated, and the remaining $40 \%$ cows were considered as neutral.

\section{Heart rate variability}

Heart rate and heart rate variability were measured weekly for the stress group, and only at the beginning and the end of the trial for the control group in order to avoid induction of stress. Measurements were done at the 6th day within the corresponding weeks, as described in Fig. 1. Heart rate recording were obtained using mobile Equine Polar H10 transmitters (Polar Electro Oy, Kempele, Finland) and Polar Equine belts equipped with electrodes. Signals were collected by the Polar Equine App (Polar Electro Oy, Kempele, Finland) installed on smartphones (Wiko Y50, Tinno, Shenzhen, China). The electrodes were positioned on the left side of the chest with one electrode placed close to the sternum and the other over the right scapula. The coat was first cleaned and water dampened, and electrode gel was applied to optimize electrode-skin contact. In weeks 0 and 4, belts were placed on 15 animals, half from the stress group and half from the control group, and recording were obtained from 10.00 to 12.00 . From 13.00 to 15.00 , recording were obtained on the remaining 15 animals. The first hour of measurement was considered as acclimatization period and associated recordings were discarded as suggested by von Borell et al. (2007). Data were first cleaned manually after visual detection of time periods with artefacts or loss of signal. Data was treated as described by Kovács et al. (2015). For analysis, 5-min time windows were selected. A total of 925 valid 5-min time windows were used for HRV analysis, 698 from stressed cows [10.0 \pm 3.7 observations per date per cow] and 227 from control ones [7.9 \pm 2.5 observations per date per cow]. The Kubios HRV software (version 2.1, Biomedical Signal Analysis Group, Department of Applied Physics, University of Kuopio, Finland) was used for HRV analysis. Means of heart rate, in beat per minute (bpm), and interbeat intervals (IBIs) were calculated. The root mean square of successive differences (RMSSD) between consecutive IBIs were calculated to assess the regularity of the heart rate. The correlation between successive IBIs, where each interval in the time series $(\mathrm{IBli}+1)$ is plotted against its successor (IBli), was evaluated through Poincaré plot analysis. Standard deviation 1 (SD1) and the ratio between standard deviation 2 (SD2) and SD1 (SD2/SD1) were calculated to analyze the discontinuity and the continuity between successive IBIs, respectively.

\section{Saliva and hair cortisol}

Saliva and hair samples were collected at the 7th day within the corresponding weeks, as described in Fig. 1, right after the morning milking and before the diet distribution. Sampling were done weekly for stress group in order to follow the dynamic of the cortisol concentration, and only at the beginning and the end of the trial for the control group in order to avoid induction of stress. Therefore, the hairs collected in the week 4 for the control group corresponded to a period and length of 4 weeks growth. To compare on a similar period and length of growth, the hair cortisol concentration of the week 1 to 4 were averaged for the stress group and compared to the hairs of the week 4 of the control group. To take into account the lag time, of one to two weeks, for cortisol deposition in the hair shaft due to its initial deposition in the hair root which is beneath the skin surface (Vesel et al., 2020), a last hair sample was collected in week 5, one week after the end of the stress period.

Saliva samples were collected using a sponge held with a string and placed inside the mouth of the cows until saturated (approx. $10 \mathrm{ml}, 1$ to $2 \mathrm{~min}$ ). The sponges were manually pressed to gather saliva, and collected samples were stored on ice, centrifuged at $2000 \times \mathrm{g}$ for 10 min to separate from feed particles (within $2 \mathrm{~h}$ after collection) and immediately frozen at 
$-20^{\circ} \mathrm{C}$ until analysis for cortisol. For analysis, samples were thawed at room temperature, vortexed and centrifuged at $1500 \times$ $\mathrm{g}$ for 15 minutes at $4^{\circ} \mathrm{C}$. Cortisol content was determined using Salimetrics extended range salivary cortisol ELISA kit (1-3002, Salimetrics, State College, PA, USA) and following manufacturer protocol as described in Schwinn et al. (2016). Repeatability of the Elisa was $4 \% \mathrm{CV}$. Hair sample were collected at the extremity of the tail switch as the hair on the tail switch grows more rapidly than other sites, and is sensitive enough to capture changes in cortisol over intervals as short as 3 weeks ${ }^{34}$. For the first hair sampling, in week 0 , the hairs were first cut at a distance of $2 \mathrm{~cm}$ from the skin, which correspond approximately to 40 days of hair growth. Hairs were collected by shaving as close as possible to the skin with an electric clipper. For the following sampling, only the re-grown hairs of the same area were collected to avoid contamination with old hairs and observe only the cortisol deposit in hair due to the current experiment. The tail switch extremity was always entirely shaved after each sampling to maximize the re-grown hair surface to collect at the following sampling and reach $250 \mathrm{mg}$ of hairs. For cows in the stress group, sampled weekly, collected regrown hairs one week after shaving were approximately 3-4 mm long, for a total weight of $486 \mathrm{mg}$ per cow in average (from 220 to 670mg). The clipper was cleaned with a brush between each animal. Hair were collected in large metallic tub, dried at room temperature for 1 week, and store at $-20^{\circ} \mathrm{C}$ until treatment. Before analysis, hairs were separated from skin follicles, dirt and faeces by mechanic sieving for 5 minutes, using 3 sieves of 400, 250 and $200 \mu \mathrm{m}$. The sieves were cleaned with a paintbrush between each individual samples. Then hair sample were washed and cortisol extracted using a protocol adapted from Tallo-Parra et al. (2014). From each sample, 250 $\mathrm{mg}$ of hair were weighed and placed into a $15-\mathrm{ml}$ conical tube. In order to evaluate chronic stress, hairs were washed by adding $2.5 \mathrm{ml}$ of isopropanol (2-propanol 99.5\%) and vortexed at 1800 r.p.m. for $2.5 \mathrm{~min}$ to remove saliva, sweat, and sebum as diffusion of cortisol to these fluids is influenced by acute stress ${ }^{36}$. The supernatant was separated by decantation and the process was repeated three times in total. The hair samples were left to dry completely for 5 days at room temperature. Washed hair samples were grounded using a ball mill, during 5 minutes at $22 \mathrm{~Hz}$ with a $12 \mathrm{~mm}$ metallic ball. For cortisol extraction, $50 \mathrm{mg}$ of grounded hair were weighted and placed into a 2-ml eppendorf tube with $1.5 \mathrm{ml}$ pure methanol and the samples were shaken at 100 r.p.m. for $18 \mathrm{~h}$ at $30^{\circ} \mathrm{C}$. Samples were centrifuged at $7000 \times \mathrm{g}$ for $2 \mathrm{~min}$ and $0.750 \mathrm{ml}$ of supernatant were transferred into a new $2-\mathrm{ml}$ eppendorf tube and then placed in an oven at $38^{\circ} \mathrm{C}$ for $24 \mathrm{H}$ to evaporate methanol. The dried extracts were reconstituted with $0.25 \mathrm{ml}$ buffer provided in the ELISA kit and stored at $-20^{\circ} \mathrm{C}$. Cortisol content was determined using Salimetrics extended range salivary cortisol ELISA kit (1-3002, Salimetrics, State College, PA, USA) following manufacturer protocol. Repeatability of the Elisa was $15.7 \% \mathrm{CV}$, whereas when taking two different subsample after grounding, reproducibility was $28 \% \mathrm{CV}$, suggesting a high cortisol variation due to extraction steps or high heterogeneity within hair powder.

\section{Blood sampling and analysis}

Samples were collected to analyse $\beta$-endorphin, glycaemia, fructosamine, thyroxine (T4) and leucocytes. Blood samples were collected weekly for stress group, and only at the beginning and the end of the trial for the control group in order to avoid induction of stress. Sampling were done at the 7th day within the corresponding weeks, as described in Fig. 1, right after the saliva sampling and before the diet distribution and the hair sampling. Sample were collected at the tail vein (vena caudalis), in yellow tubes with serum separating gel for fructosamine and T4 analysis, in green heparinized tubes to harvest plasma for $\beta$-endorphin analysis, in purples tubes with EDTA for leucocytes count and in grey tubes with antiglycolytic agent for glucose analysis, and stored on ice until treatment or analysis. Fructosamine and glucose contents were analyzed with calorimetric methods (Alinity C, Abbott ${ }^{\circledR}$ ), T4 was analyzed by chimiluminescence (Immulite 2000, Siemens ${ }^{\circledR}$ ) and leucocytes count was realized by flow cytometry (Advia, Siemens $\left.{ }^{\circledR}\right)$ at Synlab (Liège, Belgium). Treatment and analysis for $\beta$-endorphin were realized at CRA-W. Within the 30 minutes after sampling, tubes were centrifuged at $4^{\circ} \mathrm{C}, 1000 \times \mathrm{g}$ for $15 \mathrm{~min}$, and $300 \mu \mathrm{l}$ plasma were pipetted in $2 \mathrm{ml}$ tubes and preserved at $-80^{\circ} \mathrm{C}$ until analysis. Analysis of $\beta$-endorphin content were realized with Mybiosource Bovine beta-endorphin ELISA kits, (MBS2000120-96, Mybiosource Inc, CA, USA) following the manufacturer protocol and repeatability of the Elisa was $18 \% \mathrm{CV}$.

\section{Statistics}


The collected variables had different time resolution, with majority having one observation per cow per week, milk production data having one observation per cow per day, and activity and rumination having one observation per $2 \mathrm{H}$ per cow. The different time resolutions were harmonized by performing weekly averages for milk yield, activity and rumination. To take into account the intra-week variability of variables with high time resolutions (i.e. activity and rumination), the standard deviation (SD) per cow per week were calculated.

The main objective was to highlight biomarkers having equivalent distribution for stress and control group in week 0 , and having a different level in week 4, showing thus a level modification due to stress induction. Because of the long-term effect of chronic stress, it was not possible to implement a cross-over design because the stressed cows could not be moved into a non-stressed group afterward. A common practice when cross-over is not possible, such as for studies on heat stress or diseases, is to consider the individual cows effects with repeated data in time within a mixed model ${ }^{37-39}$. The duration of the experiment being limited to 4 weeks, the evolution of biomarkers was considered parallel among cows, with each cows having an individual intercept. For this, linear mixed repeated models were performed using the PROC MIXED procedure of SAS (SAS Institute, Cary, USA), with the random effect of cow being REPEATED along the weeks:

$Y_{i j k l m n}=\mu+$ group $_{i}+$ week $_{j}+$ group $_{i}{ }^{*}$ week $_{j}+\operatorname{cow}_{k}+e_{i j k l m n}$

where $\mathrm{Y}_{\mathrm{ijk}} \mathrm{m}_{\mathrm{m}}$ is the observation for the potential biomarker, $\mu=$ overall mean; group $\mathrm{p}_{\mathrm{j}}=$ the fixed effect of group $\mathrm{i}$ (control or stress); week $_{\mathrm{j}}=$ the fixed effect of week $\mathrm{j} ; \operatorname{cow}_{\mathrm{k}}=$ the random effect of cow $\mathrm{k}$ and $\mathrm{e}_{\mathrm{ijk} \mathrm{mn}}=$ the experimental error. Different covariance structures were tested for each biomarker: AR(1), ARH(1), ANTE(1), CSH, TOEP, TOEPH and UN, and the lowest AIC was selected. All the records were included in the analysis. Plots of residuals were used to ensure an approximate normal distribution and no log transformations were necessary. For each week and biomarker (dependent variable), difference of least square means were used to assess the difference between the stress and control groups. In the objective to perform a large-scale assessment of chronic stress, it would be important to know what other factors are influencing the potential biomarkers. For this purpose, more complex linear mixed models were also used to evaluate the effect of DIM, parity, breed and social position:

$Y_{i j k l m n}=\mu+\operatorname{group}_{i}+$ week $_{j}+$ group $_{i}^{*}$ week $_{j}+$ cow $_{k}+b 1 * D I M+b 2 * D_{I M}^{2}+$ parity $_{l}+$ breed $_{m}+$ socialposition $_{n}+e_{i j k l m n}$

where b1 and b2 are the regression coefficients for DIM and squared DIM (DIM2); parity $=$ the fixed effect for parity I $(1,2$ or

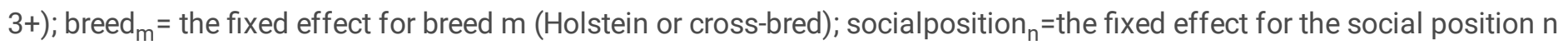
(dominant, neutral or dominated) and $\mathrm{e}_{\mathrm{ijklmn}}=$ the experimental error. The Type III sums of squares were used to determine whether these effects were significant.

\section{Results And Discussion}

Supplementary table S1 summarizes the descriptive statistics of the collected variables.

\section{Contrast between control and stress group}

\section{General variables.}

The weekly averages of the production variables for the control and stress groups are reported in the Table 1. The milk loss, compared to the previous weeks or to an expected lactation curve, seems to be an interesting chronic stress indicator. Indeed, when looking to milk yield evolution since week 0 , the decrease was more pronounced in the stress group with significant differences in week 2,3 and 4 ( $p=0.003 ; 0.004 ; 0.038$ respectively). Recent publications identified the longitudinal analysis of milk production as a tool for perturbations detection ${ }^{40-42}$. The current results seems to validate that unexpected milk losses could be used as an alert for chronic stress as well. The higher milk losses in the stress group would suggest an impact on milk production, however, differences between groups were reported as non-significant. Only few studies reported an effect of 
chronic stress on the daily milk production ${ }^{7,14}$. The stress effect on milk yield could be potentially hidden statistically by the relatively low number of observations. Anyway, the milk production is influenced by too many factors (e.g., DIM, parity, feeding) to be considered as a specific stress indicator in practical conditions. While the weight gain was apparently lower in the stress group than in the control group (33 vs $50 \mathrm{~kg}$ ), no significant differences were observed regarding the bodyweight of cows or body condition score.

Table 1. General production variables, week averages and week contrasts between control and stress groups. Stress was induced from week 1 to 4 through severe overstocking, restricted access to feed and punctual unusual events.

\begin{tabular}{|c|c|c|c|c|c|c|c|}
\hline & & & week 0 & week 1 & week 2 & week 3 & week 4 \\
\hline \multirow[t]{12}{*}{ Production variables } & \multirow[t]{3}{*}{ Milk production $24 \mathrm{~h}(\mathrm{~kg})$} & Control & 30.3 & 30.4 & 29.4 & 28.6 & 29.0 \\
\hline & & Stress & 29.7 & 29.1 & 27.2 & 26.7 & 27.3 \\
\hline & & p-value & ns & ns & ns & ns & ns \\
\hline & \multirow[t]{3}{*}{ Milk evolution since week 0 (\%) } & Control & $0.0 \%$ & $0.4 \%$ & $-2.8 \%$ & $-5.2 \%$ & $-4.0 \%$ \\
\hline & & Stress & $0.0 \%$ & $-2.1 \%$ & $-8.6 \%$ & $-10.1 \%$ & $-8.2 \%$ \\
\hline & & p-value & ns & $(*)$ & ** & ** & * \\
\hline & \multirow[t]{3}{*}{ Bodyweight (kg) } & Control & 654 & - & - & - & 704 \\
\hline & & Stress & 671 & 676 & 676 & 681 & 704 \\
\hline & & $\mathrm{p}$-value & ns & & & & ns \\
\hline & \multirow[t]{3}{*}{ BCS } & Control & 3.2 & - & - & - & 3.1 \\
\hline & & Stress & 3.2 & 3.4 & 3.4 & 3.3 & 3.2 \\
\hline & & $\mathrm{p}$-value & ns & & & & ns \\
\hline
\end{tabular}

(*) for $P \leq 0.1$; * for $P \leq 0.05$; ** for $P \leq 0.01$; *** for $P \leq 0.001$. Range and standard deviation of variables are reported in supplementary table $\mathrm{S} 1$.

\section{Behavior.}

The week averages of behavioral variables for the control and stress groups are reported in Table 2. No differences were observed in terms of activity between both groups. However, the standard deviation of activity per cow per week was higher in the stress group, in week 1 and 2 ( $p=0.002$ and 0.015 respectively). This reflects the adaption of cows observed during the experiment. To face the limited access to feed and resting areas, the cows implemented and accelerated rotation to lay and eat, resulting in a more heterogeneous activity. Consequently, the higher activity standard deviation could be quite specifically linked to the experimental design and may not necessarily be a valid biomarker for other types of chronic stress. The rumination of cows was lower in the stress group in week $1(p=0.005)$. This may also reflect the impact of the experiment on cow behaviors, especially on the restricted access to the resting area, and indirectly on rumination. Even if differences appeared in activity and rumination variables between the two studied groups, those differences were not remaining at the end of the experiment. Consequently, as mentioned earlier those variables could rather be considered as a validation of the trial impact on cow behavior, followed by an adaption to this protocol, than an indicator of chronic stress. The observations of human fear distance were not interpretable because of a difference between the two groups in week 0 . A higher number of given chasing/head-butt was observed in the stress group in week $3(p=0.002)$. This reflects on-field observations of higher negative interactions between animals in the stress group. However, this may be particularly affected by the type of stress 
induced (overstocking and restricted access to feed) and should be studied with other types of stress before attempting to consider it as a global biomarkers for chronic stress.

Table 2. Behavioral variables, week averages and week contrasts between control and stress groups. Stress was induced from week 1 to 4 through severe overstocking, restricted access to feed and punctual unusual events.

\begin{tabular}{|c|c|c|c|c|c|c|c|}
\hline & & & week 0 & week 1 & week 2 & week 3 & week 4 \\
\hline & \multirow[t]{3}{*}{ Activity (min/2 hours) } & Control & 36.6 & 36.2 & 36.6 & 35.9 & 36.0 \\
\hline & & Stress & 34.7 & 36.9 & 35.3 & 34.8 & 34.8 \\
\hline \multirow[t]{19}{*}{ Behavior } & & P-value & ns & ns & ns & ns & ns \\
\hline & \multirow[t]{3}{*}{ Activity SD (min/2 hours) ${ }^{1}$} & Control & 7.5 & 6.6 & 6.4 & 6.3 & 7.2 \\
\hline & & Stress & 7.2 & 8.8 & 8.1 & 7.6 & 6.9 \\
\hline & & P-value & ns & ** & * & $(*)$ & ns \\
\hline & \multirow[t]{3}{*}{ Rumination (min/2 hours) } & Control & 46.9 & 48.5 & 47.1 & 47.4 & 48.0 \\
\hline & & Stress & 46.3 & 45.9 & 45.9 & 45.8 & 47.4 \\
\hline & & P-value & ns & ** & ns & $(*)$ & ns \\
\hline & \multirow[t]{3}{*}{ Rumination standard deviation (min/2 hours) ${ }^{1}$} & Control & 19.7 & 19.3 & 18.8 & 19.3 & 19.9 \\
\hline & & Stress & 19.0 & 19.9 & 19.8 & 19.0 & 19.6 \\
\hline & & P-value & ns & ns & ns & ns & ns \\
\hline & \multirow[t]{3}{*}{ Human fear distance (cm) } & Control & 20.7 & 38.0 & 32.1 & 31.3 & 30.0 \\
\hline & & Stress & 46.0 & 48.7 & 48.0 & 56.0 & 53.3 \\
\hline & & P-value & * & ns & ns & ns & ns \\
\hline & \multirow[t]{3}{*}{ Chasing/Head-butt (obs/cow/hour) } & Control & 0.5 & 0.3 & 0.7 & 0.4 & 0.8 \\
\hline & & Stress & 0.3 & 0.7 & 0.4 & 1.7 & 0.7 \\
\hline & & P-value & ns & ns & ns & $\star \star$ & ns \\
\hline & \multirow[t]{3}{*}{ Grooming (obs/cow/hour) } & Control & 0.1 & 0.0 & 0.3 & 0.3 & 0.1 \\
\hline & & Stress & 0.5 & 0.1 & 0.3 & 0.0 & 0.1 \\
\hline & & P-value & $(*)$ & ns & ns & $(*)$ & ns \\
\hline
\end{tabular}

1 : activity and rumination standard deviations are calculated for individual cows on a weekly basis. (*) for $P \leq 0.1$; * for $P \leq$ 0.05 ; $* *$ for $P \leq 0.01 ; * \star \star$ for $P \leq 0.001$. Range and standard deviation of variables are reported in supplementary table $S 1$.

\section{Heart rate variability.}

The week averages of heart rate variables for the control and stress groups are reported in Table 3 . Whereas no differences were observed between groups in week 0 , the heart rate was lower in the stress group in week $4(p=0.014)$, and the inter-beat interval was higher $(p=0.001)$. At the end of the experiment, the RMSSD was higher for the stress group $(p=0.002)$, showing more heterogeneity in the heart rate. Both a higher SD1 $(p=0.002)$ and a lower SD2/SD1 ratio $(p=0.007)$ showed a more important discontinuity between successive IBIs in the stress group. While von Borell et al. (2007) reported an increase in stress load associated with a decrease in RMSSD and Mohr et al. (2002) did not observed differences between stress groups of calves, the current results are in line with the conclusions of Kovács et al. (2015). Indeed, from a comparison of lame and 
healthy cows, they concluded that heart rate was lower in lame cows than in non-lame ones, parasympathetic measures in the time domain (RMSSD) were higher, and the indices of sympathovagal balance (SD2/SD1) were lower in lame cows than in sound cows. The current results validate the conclusions of Kovács et al. (2015) that HRV analysis is an interesting method in the assessment of chronic stress. While the heart rate and IBIs values were different in the stress group between week 0 and week 4, the RMSSD, SD1 and SD2/SD1 remained relatively stable and changes were observed in the control group. A hypothesis to explain this would be the removing of cows from the original herd to constitute the stress group, and consequently a decreased stocking density in the control group. This may induce a lower stress load for the control group in weeks 1 to 4 .

Table 3. Heart rate variability, week averages and week contrasts between control and stress groups. Stress was induced from week 1 to 4 through severe overstocking, restricted access to feed and punctual unusual events.

\begin{tabular}{|c|c|c|c|c|c|c|c|}
\hline & & & week 0 & week 1 & week 2 & week 3 & week 4 \\
\hline & \multirow[t]{3}{*}{ Heart rate $(\mathrm{bpm})^{2}$} & Control & 84.7 & - & - & - & 85.6 \\
\hline & & Stress & 83.6 & 81.2 & 72.6 & 80.8 & 78.1 \\
\hline \multirow[t]{13}{*}{ Heart rate } & & P-value & ns & & & & * \\
\hline & \multirow[t]{3}{*}{$\mathrm{IBIs}(\mathrm{ms})^{2}$} & Control & 718.6 & - & - & - & 710.2 \\
\hline & & Stress & 726.1 & 749.9 & 833.4 & 752.7 & 776.9 \\
\hline & & P-value & ns & & & & $\star \star$ \\
\hline & \multirow[t]{3}{*}{$\operatorname{RMSSD}(\mathrm{ms})^{2}$} & Control & 11.6 & - & - & - & 9.5 \\
\hline & & Stress & 13.9 & 14.9 & 14.2 & 15.0 & 14.1 \\
\hline & & P-value & ns & & & & ** \\
\hline & \multirow[t]{3}{*}{$\mathrm{SD} 1(\mathrm{~ms})^{2}$} & Control & 8.2 & - & - & - & 6.7 \\
\hline & & Stress & 9.8 & 10.6 & 10.1 & 10.6 & 10.0 \\
\hline & & P-value & ns & & & & ** \\
\hline & \multirow[t]{3}{*}{$\mathrm{SD} 2 / \mathrm{SD} 1^{2}$} & Control & 3.4 & - & - & - & 3.8 \\
\hline & & Stress & 3.0 & 3.0 & 3.0 & 3.0 & 3.1 \\
\hline & & P-value & $(\star)$ & & & & $\star \star$ \\
\hline
\end{tabular}

(*) for $\mathrm{P} \leq 0.1$; * for $\mathrm{P} \leq 0.05$; ** for $\mathrm{P} \leq 0.01$; $* \star *$ for $\mathrm{P} \leq 0.001$; IBIs: heart interbeat intervals; RMSSD : root mean square of successive differences between consecutive IBIs; SD1: Standard deviation 1 of the Poincaré plot; SD1/SD2: ratio between standard deviation 2 of the Poincaré plot and SD1. Range and standard deviation of variables are reported in supplementary table S1.

\section{Biochemical biomarkers.}

The week averages of the biochemical biomarkers for the control and stress groups are reported in Table 4. There were no differences between both groups regarding the salivary cortisol. This validates that the salivary cortisol is not an indicator of chronic stress and should be more relevant to assess acute stress ${ }^{8}$. Hair cortisol contents were in similar ranges than previous studies ${ }^{21,27,44}$ although slightly higher. Whereas the hair cortisol level was similar between both groups at week 0 , a difference ( $p$ <.0001) was observed on hairs grown between week 1 and week 4 with higher cortisol in the stress group ( $36.2 \mathrm{pg} / \mathrm{mg}$ in the stress group vs $21.5 \mathrm{pg} / \mathrm{mg}$ in the control group). Hair cortisol content was analyzed in the stress group with a finer timer frequency of one week. The dynamic evolution of hair cortisol is plotted in Figure 2. In the stress group, the 
hair cortisol was 3.6 times greater in week 4 than in week 0 (52 vs 16.5 pg/mg). Hair cortisol increased consecutively in week 1 and 2, decreased in week 3 and sharply increased in week 4 . The reason for the decrease in week 3 is not explained. However, the sharp increase from week 3 to week 4 seems to indicate that the stress load did not disappear even if the hair cortisol was relatively low in week 3 . To take into account the lag time, of one to two weeks, for cortisol deposition in the hair shaft due to its initial deposition in the hair root which is beneath the skin surface ${ }^{17}$, a last hair sample was collected in week 5 , one week after the end of the stress period. Surprisingly, in the week 5 the hair cortisol content considerably decreased in the stress group compared to week 4, with 24.8 and $18.4 \mathrm{pg} / \mathrm{mg}$ in the control and stress groups, respectively. In order to evaluate chronic stress, hairs were washed with isopropanol to remove saliva, sweat, and sebum as diffusion of cortisol to these fluids is influenced by acute stress ${ }^{36}$. Despite this, the cortisol content in regrown hairs was enough reactive in time to show strong variation from week to week. Compared to others studies, this may be due to the particularity of the weekly shave/reshave methodology which is not a common practice. It enables to consider only the cortisol of the hairs grown in the past week and supposes a strong spatial gradient of cortisol in the hairs following the past stress events. The decrease in week 5 suggests that the deposit of cortisol stopped almost immediately after the end of stress and also that the time lag considered for the growth of the hair from the roots to the skin surface is below one week. Considering those dynamic aspects, the hair cortisol seems to be a biomarker of chronic stress as it increases progressively with the stress duration. The cortisol content in the growing hairs is reacting rapidly to the stress load, within one week, and the hair length collected would directly affect the analytical results. As mentioned by Vesel et al. (2020), not enough is known about the mechanisms of cortisol deposition in hair, and further researches would be needed to better understand the evolution of hair cortisol regarding spatial location within the hair and through time, especially with longer stress periods. Also, if hair cortisol is mainly accumulating through blood, while blood cortisol return to a baseline level after long term stress it might be expected a decrease in hair cortisol content as well. This might be a second hypothesis for the decrease in week 5 in the stress group. Regarding glycaemia, there was no difference between the stress and control groups, suggesting that glucose is not a relevant biomarker for chronic stress, potentially due to acute oscillation through time (Jensen et al., 1993), or that preceding saliva sampling was stressful and induced biases on glucose. Alternatively, a different level of fructosamine was observed in week 4 between the control and stress groups $(p=0.035)$. Fructosamine is formed by a reaction between glucose and protein, and because of its long half-life in cattle (i.e. 16 days) it reflects the plasma glucose for the previous 1-3 weeks ${ }^{46}$, without being affected by acute oscillation of plasma glucose. Its concentration has been mainly used as an indicator of undernutrition and energy deficit ${ }^{47}$. The higher content of blood fructosamine in the stress group suggests an impact of the chronic stress on energy metabolism, and especially on glucose, reflected on the long term through the fructosamine content. This effect might be masked on glycaemia because of acute oscillations over time. The dynamic evolution of blood fructosamine is plotted in Figure 3. The graph shows that the level only increased in week 3 , validating that fructosamine reflects long term impact on glycaemia as it increased 3 weeks after the start of stress. Therefore, to assess the real effect of the 4 weeks stress, it would be needed to perform a longer sampling period to analyze fructosamine content for two additional weeks after the end of stress. The higher level in the stress group in week 4 suggests that blood fructosamine content could be considered as a biomarker of chronic stress, however it is not specific as potentially also affected by nutrition and energy balance. Finally, there were no differences between the stress and control groups regarding the blood $\beta$ endorphin and T4.

Table 4. Molecules in hair, saliva and blood, week averages and week contrasts between control and stress groups. Stress was induced from week 1 to 4 through severe overstocking, restricted access to feed and punctual unusual events. 


\begin{tabular}{|c|c|c|c|c|c|c|c|}
\hline & & & week 0 & week 1 & week 2 & week 3 & week 4 \\
\hline \multirow[t]{18}{*}{ Biochemical biomarkers } & \multirow[t]{3}{*}{ Salivary cortisol $(\mu \mathrm{g} / \mathrm{dL})$} & Control & 0.20 & - & - & - & 0.15 \\
\hline & & Stress & 0.21 & 0.16 & 0.20 & 0.16 & 0.12 \\
\hline & & P-value & ns & & & & ns \\
\hline & \multirow[t]{3}{*}{ Hair cortisol (pg/mg) } & Control & 19.3 & - & - & - & 21.5 \\
\hline & & Stress & 16.5 & - & - & - & $36.2^{1}$ \\
\hline & & P-value & ns & & & & $\star \star \star ~$ \\
\hline & \multirow[t]{3}{*}{ Blood Glucose (mg/dL) } & Control & 64.1 & - & - & - & 58.9 \\
\hline & & Stress & 63.9 & 62.9 & - & 63.7 & 57.8 \\
\hline & & P-value & ns & & & & ns \\
\hline & \multirow[t]{3}{*}{ Blood Fructosamine $(\mu \mathrm{Mol} / \mathrm{I})$} & Control & 227 & - & - & - & 228 \\
\hline & & Stress & 223 & 218 & 211 & 242 & 240 \\
\hline & & P-value & ns & & & & * \\
\hline & \multirow[t]{3}{*}{ Blood $\beta$-endorphin (pg/ml) } & Control & 240.4 & - & - & - & 211.9 \\
\hline & & Stress & 226.2 & 252.8 & 292.9 & 269.9 & 229.1 \\
\hline & & P-value & ns & & & & ns \\
\hline & \multirow[t]{3}{*}{ Blood T4 $(\mu \mathrm{g} / \mathrm{L})$} & Control & 37.2 & - & - & - & 47.6 \\
\hline & & Stress & 37.6 & 38.6 & 41.7 & 44.8 & 47.0 \\
\hline & & P-value & ns & & & & ns \\
\hline
\end{tabular}

$\left.{ }^{*}\right)$ for $\mathrm{P} \leq 0.1 ; *$ for $\mathrm{P} \leq 0.05 ; * *$ for $\mathrm{P} \leq 0.01 ; * \star *$ for $\mathrm{P} \leq 0.001 ;{ }^{1}$ hairs collected in control and stress group both corresponded to the period of growth from week 1 to week 4 but with a different shaving frequency. Range and standard deviation of variables are reported in supplementary table S1.

\section{Leucocytes.}

The week averages of the leucocytes for the control and stress groups are reported in Table 5. There were no differences between both groups regarding the different white blood cells whereas chronic stress has been reported to modify the immune status of cows ${ }^{7}$. Although it is not significant, some differences can be observed in the stress group between week 0 and 4 (i.e. neutrophils decreased by $8 \%$ and eosinophils increased by $15 \%$ while control levels remained stable). It is plausible that a higher number of observations would have allowed to statistically highlight those differences. Anyway, as for the milk losses, the activity or the fructosamine, the leucocyte profile could potentially be affected by other factors and it would be difficult to consider it as a specific biomarker of chronic stress.

Table 5. Leucocyte profile, week averages and week contrasts between control and stress groups. Stress was induced from week 1 to 4 through severe overstocking, restricted access to feed and punctual unusual events. 


\begin{tabular}{|c|c|c|c|c|c|c|c|}
\hline & & & week 0 & week 1 & week 2 & week 3 & week 4 \\
\hline \multirow[t]{21}{*}{ Leucocytes } & \multirow[t]{3}{*}{ Blood leucocytes (/mm3) } & Control & 7751 & - & - & - & 7942 \\
\hline & & Stress & 7051 & 7079 & 7389 & 6404 & 7031 \\
\hline & & $\mathrm{p}$-value & ns & & & & $(*)$ \\
\hline & \multirow[t]{3}{*}{$\mathrm{PMN}(/ \mathrm{mm} 3)$} & Control & 3687 & - & - & - & 3611 \\
\hline & & Stress & 3338 & 3488 & 3598 & 3044 & 3200 \\
\hline & & p-value & ns & & & & ns \\
\hline & \multirow[t]{3}{*}{ Blood Neutrophils /mm3) } & Control & 2972 & - & - & - & 2921 \\
\hline & & Stress & 2713 & 2678 & 2807 & 2456 & 2499 \\
\hline & & $\mathrm{p}$-value & ns & & & & ns \\
\hline & \multirow[t]{3}{*}{ Blood Eosinophils (/mm3) } & Control & 645 & - & - & - & 626 \\
\hline & & Stress & 557 & 752 & 727 & 528 & 641 \\
\hline & & p-value & ns & & & & ns \\
\hline & \multirow[t]{3}{*}{ Blood Basophils (/mm3) } & Control & 70 & - & - & - & 64 \\
\hline & & Stress & 68 & 54 & 64 & 59 & 61 \\
\hline & & $\mathrm{p}$-value & ns & & & & ns \\
\hline & \multirow[t]{3}{*}{ Blood Lymphocytes (/mm3) } & Control & 3635 & - & - & - & 3823 \\
\hline & & Stress & 3250 & 3113 & 3291 & 2984 & 3402 \\
\hline & & p-value & ns & & & & ns \\
\hline & \multirow[t]{3}{*}{ Blood Monocytes (/mm3) } & Control & 427 & - & - & - & 506 \\
\hline & & Stress & 463 & 479 & 501 & 373 & 429 \\
\hline & & p-value & ns & & & & ns \\
\hline
\end{tabular}

$\left.{ }^{*}\right)$ for $\mathrm{P} \leq 0.1$; * for $\mathrm{P} \leq 0.05$; ** for $\mathrm{P} \leq 0.01$; $* *$ for $\mathrm{P} \leq 0.001$. Range and standard deviation of variables are reported in supplementary table $\mathrm{S} 1$.

\section{Influence of other factors on the potential biomarkers}

In the objective to perform a large-scale assessment of chronic stress, it would be important to know what other factors are influencing the highlighted biomarkers. Additional linear mixed repeated models were used to evaluate the effect of group, week, group*week, DIM, DIM², parity, breed and social position. The results are shown in Table 6. Among the interesting points to note, the milk loss was not affected by DIM, parity, breed or social position. This is due to the fact that milk loss is proper to each individual cow and has a relative scale regarding DIM. It is consequently an alert tool relatively easy to implement, without the need to consider those effects. Regarding the biomarkers of interest, Table 6 also shows a significant effect of parity and breed on hair cortisol. The least square mean estimates from the mixed models shown that hair cortisol was higher for Holstein than for crossbred cows with 29.1 and $19.8 \mathrm{pg} / \mathrm{mg}$ respectively. It validates the observations of Peric et al. (2013) of higher hair cortisol content for Holstein that for crossbreed F1. It would imply that for an equivalent stress load and perception, the absolute level of cortisol would be different because of slight physiological differences between breeds. This breed effect has an impact on a potential large-scale use of hair cortisol to monitor stress. It means that the 
absolute value cannot be used as such and it should be considered to take into account the breed effect (e.g., expressing result as difference from expected breed values). The hair cortisol content also decreased with parity, with levels of 26.1, 23.2 and $20.2 \mathrm{pg} / \mathrm{mg}$ for parity 1,2 and $>3$. While Burnett et al. (2014) found relatively similar content between primiparous and multiparous ( $p=0.1$ ), the current results validate the findings obtained by González-de-la-Vara et al. (2011) who observed lower hair cortisol for older cows and the conclusions of Heimbürge et al. (2019) describing for several species a tendency of hair cortisol to decline with age. As suggested by Burnett et al. (2014), it could be due to the higher stress perceived by primiparous cows because of all the changes induced by the first lactation and the integration to the productive herd. It would be needed to evaluate if the different cortisol content reflect a different stress level, or if this is only due to biological evolution with age as suggested by Heimbürge et al. (2019). If the cortisol is physiologically more elevated for primiparous for a similar stress level, this parity effect would have an impact on a potential large-scale use of hair cortisol to monitor stress and should be considered (e.g., expressing result as difference from expected parity values).

Table 6. Effect of other factors of interest on the observed variables 


\begin{tabular}{|c|c|c|c|c|c|c|c|c|c|c|}
\hline & & intercept & group & week & group*week & DIM & $\mathrm{DIM}^{2}$ & parity & breed & $\begin{array}{l}\text { social } \\
\text { position }\end{array}$ \\
\hline \multirow[t]{4}{*}{$\begin{array}{l}\text { Production } \\
\text { variables }\end{array}$} & $\begin{array}{l}\text { Milk } \\
\text { production } \\
24 \mathrm{~h}(\mathrm{~kg})\end{array}$ & *** & ns & *** & * & *** & ** & ns & ns & ns \\
\hline & $\begin{array}{l}\text { Milk evolution } \\
\text { since week } 0 \\
(\%)\end{array}$ & $* * *$ & ** & $\star \star \star$ & * & ns & ns & ns & ns & ns \\
\hline & Weight (kg) & $* * *$ & ns & $\star \star \star$ & ** & ns & ns & $\star \star \star *$ & ns & ns \\
\hline & BCS & *** & ns & * & ns & ns & ns & ns & * & ns \\
\hline \multirow[t]{7}{*}{ Behavior } & $\begin{array}{l}\text { Activity (min/2 } \\
\text { hours) })^{1}\end{array}$ & *** & ns & $\star * \star$ & $\star * *$ & * & ** & * & ns & ns \\
\hline & $\begin{array}{l}\text { Activity SD } \\
(\mathrm{min} / 2 \text { hours })^{1}\end{array}$ & ** & ns & * & $* * *$ & ns & ns & $(*)$ & ns & ns \\
\hline & 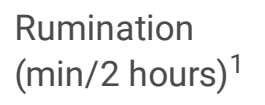 & *** & ns & ** & ** & ns & ns & ns & ns & ns \\
\hline & $\begin{array}{l}\text { Rumination } \\
\text { SD (min/2 } \\
\text { hours) }{ }^{1}\end{array}$ & $\star * *$ & ns & ns & $(\star)$ & ns & ns & ns & $(*)$ & ns \\
\hline & $\begin{array}{l}\text { Human fear } \\
\text { distance (cm) }\end{array}$ & * & ns & ns & ns & ns & ns & ns & ns & ns \\
\hline & $\begin{array}{l}\text { Chasing/Head- } \\
\text { butt } \\
\text { (obs/hour) }\end{array}$ & ns & ns & ns & * & ns & ns & ns & ns & ns \\
\hline & $\begin{array}{l}\text { Grooming } \\
\text { (obs/hour) }\end{array}$ & ns & ns & ** & $(\star)$ & ns & ns & ns & ns & ns \\
\hline \multirow[t]{5}{*}{ Heart rate } & $\begin{array}{l}\text { Heart rate } \\
\text { mean }(\mathrm{bpm})^{2}\end{array}$ & *** & ns & 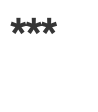 & $(*)$ & ns & ns & ns & ns & ns \\
\hline & IBIs $(m s)^{2}$ & *** & ns & $\star \star \star *$ & $(*)$ & ns & ns & ns & ns & ns \\
\hline & $\operatorname{RMSSD}(\mathrm{ms})^{2}$ & $\star *$ & * & ns & ns & ns & ns & ns & ns & ns \\
\hline & $\mathrm{SD} 1(\mathrm{~ms})^{2}$ & $\star *$ & * & ns & ns & ns & ns & ns & ns & ns \\
\hline & $\mathrm{SD} 2 / \mathrm{SD} 1^{2}$ & $* \star *$ & * & ns & ns & ns & ns & ns & ns & ns \\
\hline \multirow[t]{5}{*}{$\begin{array}{l}\text { Biochemical } \\
\text { biomarkers }\end{array}$} & $\begin{array}{l}\text { Salivary } \\
\text { cortisol } \\
(\mu \mathrm{g} / \mathrm{dL})\end{array}$ & $(*)$ & ns & ** & ns & ns & ns & ns & ns & ns \\
\hline & $\begin{array}{l}\text { Hair cortisol } \\
(\mathrm{pg} / \mathrm{mg})\end{array}$ & $\star \star \star *$ & ** & $\star \star \star *$ & $\star * *$ & ns & ns & ** & $\star \star$ & ns \\
\hline & $\begin{array}{l}\text { Blood Glucose } \\
(\mathrm{mg} / \mathrm{dL})\end{array}$ & $\star \star * *$ & ns & $\star \star \star *$ & ns & ns & ns & ns & ns & ns \\
\hline & $\begin{array}{l}\text { Blood } \\
\text { Fructosamine } \\
\text { ( } \mu \mathrm{Mol} / \mathrm{I})\end{array}$ & $\star \star \star *$ & ns & 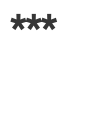 & * & ns & ns & ns & ns & ns \\
\hline & $\begin{array}{l}\text { Blood } \beta \text { - } \\
\text { endorphin } \\
(\mathrm{pg} / \mathrm{ml})\end{array}$ & $\left(^{\star}\right)$ & ns & ns & ns & ns & ns & ns & ns & ns \\
\hline
\end{tabular}

Page 15/22 


\begin{tabular}{|c|c|c|c|c|c|c|c|c|c|c|}
\hline & $\begin{array}{l}\text { Blood T4 } \\
(\mu \mathrm{g} / \mathrm{L})\end{array}$ & $\star \star \star$ & ns & $\star * \star$ & ns & ns & ns & ns & ns & $(*)$ \\
\hline \multirow[t]{7}{*}{ Leucocytes } & $\begin{array}{l}\text { Blood } \\
\text { leucocytes } \\
\text { (/mm3) }\end{array}$ & ** & ns & ** & ns & ns & ns & * & ns & ns \\
\hline & PMN (/mm3) & ns & ns & * & ns & ns & ns & ns & ns & ns \\
\hline & $\begin{array}{l}\text { Blood } \\
\text { Neutrophils } \\
\text { /mm3) }\end{array}$ & ns & ns & ns & ns & ns & ns & ns & ns & ns \\
\hline & $\begin{array}{l}\text { Blood } \\
\text { Eosinophils } \\
\text { (/mm3) }\end{array}$ & ns & ns & ns & ns & ns & ns & ns & ns & $(*)$ \\
\hline & $\begin{array}{l}\text { Blood } \\
\text { Basophils } \\
\text { (/mm3) }\end{array}$ & ** & ns & ns & ns & ns & ns & * & ns & ns \\
\hline & $\begin{array}{l}\text { Blood } \\
\text { Lymphocytes } \\
\text { (/mm3) }\end{array}$ & ** & ns & * & ns & ns & ns & $\star \star$ & ns & ns \\
\hline & $\begin{array}{l}\text { Blood } \\
\text { Monocytes } \\
\text { (/mm3) }\end{array}$ & $(*)$ & ns & * & $(\star)$ & ns & ns & $(*)$ & ns & ns \\
\hline
\end{tabular}

(*) for $P \leq 0.1 ;$ * for $P \leq 0.05 ;$ ** for $P \leq 0.01 ; * \star *$ for $P \leq 0.001$

\section{Perspectives and limitations}

In this experiment, several potential biomarkers appeared to have a different level between the control and stress groups after 4 weeks stress. First, the milk yield losses of individual cows seem to be an efficient alert system to detect troubles, including chronic stress. Milk yield is daily available in many farms, hence it could be an easy tool to implement at a large scale. As the milk loss is not a specific biomarker, it could constitute a general alert system, being complementary to more specific monitoring tools. Activity standard deviation and rumination may be particularly affected by the type of stress induced (overstocking and restricted access to feed) and should be studied with other types of stress before attempting to consider it as a global biomarkers for chronic stress. Heart rate and heart rate variability seems to be relevant biomarkers of chronic stress. Nonetheless, the recording is costly and time consuming, while the treatment of collected data is complex and difficult to automate. Consequently, it does not seem feasible to assess chronic stress in commercial farms at a large scale using this methodology. Regarding the biochemical biomarkers, the fructosamine level in blood seems to be affected by chronic stress as well. It has the advantage of not being sensible to acute time dependent oscillation, facilitating the sampling methodology. This analytical measure is commonly available through veterinary labs, although blood sampling is invasive and potentially regulated by ethic committees. However, the fructosamine content is mainly affected by nutrition and energy balance, and is therefore not a specific biomarker of chronic stress. Finally, the hair cortisol content showed an intense and significant increase in the stress group. The collection of hair is simple, non-invasive and samples can be stored at room temperature. It is consequently more adapted to large scale sampling than other variables. Even if the mechanisms of deposition in hair and the dynamics through time are not fully understood, it seems to be the most promising indicator to assess chronic stress.

Those preliminary results would need to be validated before drawing general conclusions. This research takes place in the frame of a more global project, the Interreg NWE HappyMoo project, aiming to monitor the welfare status of cows, and it is planned as a next step to duplicate the experiment with another herd in order to validate those preliminary results.

Additionally, in the objective of large scale monitoring of stress status of cows, the easiest way would be to go through the milk analysis, as it is routinely accessible, cheap and non-invasive. During the experiment, milk samples were collected and it 
is planned to evaluate if fine milk composition, or predictions from mid-infrared analysis of milk, can be considered as biomarkers of chronic stress as well. This could also broaden the possibilities to detect, to manage and to breed for stress resilience, beyond current strategies focusing mainly on heat-stress.

\section{Conclusions}

The goal of this study was to compare and assess the relevance of several potential biomarkers of chronic stress. Among the collected variables, the milk loss, the heart rate variability, the blood fructosamine and the hair cortisol were significantly different at the end of the stress period between the stress and control groups. Whereas the milk loss seemed to be an effective and easy way to detect general troubles, including stress, the hair cortisol content seemed to be the most promising indicator to assess chronic stress in commercial farms

\section{Declarations}

\section{DATA AVAILABILITY}

Correspondence and requests for data should be addressed to corresponding authors.

\section{CONSORTIUM}

Julie Leblois ${ }^{1}$, Carlo Bertozzi ${ }^{1}$, Marie-Nguyet $\operatorname{Tran}^{1}$, Romain Reding ${ }^{2}$, Virginie Vanden Dries ${ }^{3}$, Clément Grelet ${ }^{3}$, Frédéric Dehareng $^{3}$, Jean-Pierre Allard ${ }^{4}$, Guillaume Courtois ${ }^{4}$, Christophe Lecomte ${ }^{5}$, Luc Manciaux ${ }^{5}$, Corine Portemont ${ }^{5}$, Morgane Hoenen ${ }^{5}$, Nicolas Gaudillère ${ }^{5}$, Pauline Woehrle ${ }^{5}$, Manon Jattiot ${ }^{5}$, Marion Calmels ${ }^{5}$, Valérie Wolf ${ }^{5}$, Fatima Ezzahra Bouzidi Idrissi $^{5}$, Daragh Matthews ${ }^{6}$, Mike Lynch ${ }^{6}$, Marine Gelé ${ }^{7}$, Luc Mirabito ${ }^{7}$, Mahommed El Jabri ${ }^{7}$, Laura Dale ${ }^{8}$, Andreas Werner $^{8}$, Tatjana Heim ${ }^{8}$, Elisa Strang ${ }^{8}$, Kevin Klever ${ }^{9}$, Robert Strumpen ${ }^{9}$, Peter Höckels ${ }^{9,10}$, Martin Busfield ${ }^{11}$, Urs Schuler ${ }^{11}$, Nicolas Gengler $^{13}$, Hélène Soyeurt ${ }^{13}$, Anthony Tedde ${ }^{13}$, Sébastien Franceschini ${ }^{13}$.

${ }^{1}$ Elevéo asbl by awé groupe, Belgium

2 CONVIS s.c. Luxembourg

${ }^{3}$ Walloon Agricultural Research Center (CRA-W), Belgium

${ }^{4}$ ESTEL Numérique France

${ }^{5}$ France Conseil Elevage, France

${ }^{6}$ Irish Cattle Breeding Federation Society Limited Ireland

${ }^{7}$ French Livestock Institute (IDELE), France

${ }^{8}$ Regional association for performance testing in livestock breeding of Baden-Württemberg, Germany

${ }^{9}$ State Control Association of North Rhine-Westphalia, Germany

${ }^{10}$ Institute for milk testing GmbH \& Co. KG, Germany

${ }^{11}$ National Milk Records PLC, United Kingdom

12 Qualitas AG, Switzerland 
${ }^{13}$ University of Liège, Gembloux Agro-Bio Tech (ULiège-GxABT), Belgium

\section{ACKNOWLEDGEMENTS}

HappyMoo project has received funding from INTERREG NWE under grant agreement $\mathrm{n}^{\circ}$ NWE730 and from the Walloon Region. The authors gratefully thank François Rouelle, Maxence Didelez, Sophie Mathieux, Maxime Druez, Quentin Vigneron, Mohamed El Morabit, Matthieu Dubuisson, Octave Christophe, Petimat Kitaeva \& Olivier Genard for their highly precious work. The authors also acknowledge Virginie Decruyenaere, Eric Froidmont and Pierre Rondia for their help.

\section{AUTHOR CONTRIBUTIONS}

Experimental set-up and design: CG, VV, JL, LM, JW, FD ; Ethical protocol: CG, VV, JW; Data acquisition: CG, VV, JL, JW; Practical analyses: CG, VV, FD; Statistical analyses: CG, VV; HS, SF, YB, NG; Manuscript and figures preparation: CG; All authors read and approved this article.

\section{ADDITIONAL INFORMATION}

The author(s) declare no competing interests. All financial supports are identified in the Acknowledgements.

\section{References}

1. Brito, L. F. et al. Large-Scale Phenotyping of Livestock Welfare in Commercial Production Systems: A New Frontier in Animal Breeding. Frontiers in Genetics vol. 11793 (2020).

2. Selye, H. A syndrome produced by diverse nocuous agents [13]. Nature vol. 138 (1936).

3. Selye, H. Stress and the general adaptation syndrome. Br. Med. J. 1, (1950).

4. Selye, H. Stress without Distress BT - Psychopathology of Human Adaptation. Serban G. (eds). Psychopathol. Hum. Adapt. (1976).

5. Selye Hans. HISTORY AND GENERAL OUTLINE OF THE STRESS CONCEPT. in Stress in Health and Disease (1976). doi:10.1016/b978-0-407-98510-0.50009-4.

6. Fink, G. Stress: Definition and history. in Encyclopedia of Neuroscience (2009). doi:10.1016/B978-008045046-9.00076-0.

7. Trevisi, E. \& Bertoni, G. Some physiological and biochemical methods for acute and chronic stress evaluation in dairy cows. Ital. J. Anim. Sci. 8, 265-286 (2009).

8. Mormède, P. et al. Exploration of the hypothalamic-pituitary-adrenal function as a tool to evaluate animal welfare. Physiol. Behav. 92, 317-339 (2007).

9. Kovács, L. et al. Heart rate variability as an indicator of chronic stress caused by lameness in dairy cows. PLoS One 10, (2015).

10. Moberg, G. P., Anderson, C. O. \& Underwood, T. R. Ontogeny of the adrenal and behavioral responses of lambs to emotional stress. J. Anim. Sci. 51, (1980).

11. Romero, L. M. Physiological stress in ecology: Lessons from biomedical research. Trends in Ecology and Evolution vol. 19 (2004).

12. Dobson, H. \& Smith, R. F. What is stress, and how does it affect reproduction? in Animal Reproduction Science vols 60$61(2000)$.

13. Walker, S. L., Smith, R. F., Jones, D. N., Routly, J. E. \& Dobson, H. Chronic stress, hormone profiles and estrus intensity in dairy cattle. Horm. Behav. 53, 493-501 (2008). 
14. Tallo-Parra, O., Carbajal, A., Monclús, L., Manteca, X. \& Lopez-Bejar, M. Hair cortisol and progesterone detection in dairy cattle: interrelation with physiological status and milk production. Domest. Anim. Endocrinol. 64, 1-8 (2018).

15. Friend, T. H., Dellmeier, G. R. \& Gbur, E. E. Comparison of four methods of calf confinement. I. Physiology. J. Anim. Sci. 60, (1985).

16. Fisher, A. D., Crowe, M. A., Prendiville, D. J. \& Enright, W. J. Indoor space allowance: Effects on growth, behaviour, adrenal and immune responses of finishing beef heifers. Anim. Sci. 64, (1997).

17. Vesel, U., Pavič, T., Ježek, J., Snoj, T. \& Starič, J. Welfare assessment in dairy cows using hair cortisol as a part of monitoring protocols. J. Dairy Res. 87, (2020).

18. Heimbürge, S., Kanitz, E. \& Otten, W. The use of hair cortisol for the assessment of stress in animals. Gen. Comp. Endocrinol. 270, 10-17 (2019).

19. Ito, N. et al. Human hair follicles display a functional equivalent of the hypothalamic-pituitary-adrenal (HPA) axis and synthesize cortisol. FASEB J. 19, 1332-1334 (2005).

20. Meyer, J. S. \& Novak, M. A. Minireview: Hair cortisol: A novel biomarker of hypothalamic-pituitary-adrenocortical activity. Endocrinology vol. 153 (2012).

21. Comin, A. et al. Hair cortisol as a marker of hypothalamic-pituitary-adrenal axis activation in Friesian dairy cows clinically or physiologically compromised. Livest. Sci. 152, (2013).

22. Burnett, T. A. et al. Relationship of concentrations of cortisol in hair with health, biomarkers in blood, and reproductive status in dairy cows. J. Dairy Sci. 98, (2015).

23. Tallo-Parra, O. et al. Acute ACTH-induced elevations of circulating cortisol do not affect hair cortisol concentrations in calves. Gen. Comp. Endocrinol. 240, (2017).

24. Burnett, T. A. et al. Relationship of concentrations of cortisol in hair with health, biomarkers in blood, and reproductive status in dairy cows. J. Dairy Sci. 98, 4414-4426 (2015).

25. Braun, U., Clavadetscher, G., Baumgartner, M. R., Riond, B. \& Binz, T. M. Hair cortisol concentration and adrenal gland weight in healthy and ill cows. Schweizer Archiv fur Tierheilkunde vol. 159 (2017).

26. Creutzinger, K. C. et al. An investigation of hair cortisol as a measure of long-term stress in beef cattle: Results from a castration study. Can. J. Anim. Sci. 97, (2017).

27. González-de-la-Vara, M. del R. et al. Effects of adrenocorticotropic hormone challenge and age on hair cortisol concentrations in dairy cattle. Can. J. Vet. Res. 75, (2011).

28. von Borell, E. et al. Heart rate variability as a measure of autonomic regulation of cardiac activity for assessing stress and welfare in farm animals - A review. Physiology and Behaviorvol. 92 (2007).

29. Waiblinger, S. et al. Assessing the human-animal relationship in farmed species: A critical review. Appl. Anim. Behav. Sci. 101, 185-242 (2006).

30. Comin, A. et al. Hair cortisol levels in dairy cows from winter housing to summer highland grazing. Elsevier.

31. Schubach, K. M. et al. Impacts of stocking density on development and puberty attainment of replacement beef heifers. Animal 11, 2260-2267 (2017).

32. Ferguson, J. D., Galligan, D. T. \& Thomsen, N. Principal Descriptors of Body Condition Score in Holstein Cows. doi:10.3168/jds.S0022-0302(94)77212-X.

33. Schwinn, A. C., Knight, C. H., Bruckmaier, R. M. \& Gross, J. J. Suitability of saliva cortisol as a biomarker for hypothalamic-pituitary-adrenal axis activation assessment, effects of feeding actions, and immunostimulatory challenges in dairy cows. J. Anim. Sci. 94, 2357-2365 (2016).

34. Burnett, T. A. et al. Short communication: Factors affecting hair cortisol concentrations in lactating dairy cows. J. Dairy Sci. 97, (2014).

35. Tallo-Parra, O., Manteca, X., Sabes-Alsina, M., Carbajal, A. \& Lopez-Bejar, M. Hair cortisol detection in dairy cattle by using EIA: Protocol validation and correlation with faecal cortisol metabolites. Anima/ 9, 1059-1064 (2014).

Page 19/22 
36. Nedić, S. et al. Cortisol concentrations in hair, blood and milk of Holstein and Busha cattle. Slov. Vet. Res. 54, 163-172 (2017).

37. Bjerre-Harpøth, V. et al. Metabolic and production profiles of dairy cows in response to decreased nutrient density to increase physiological imbalance at different stages of lactation. J. Dairy Sci. 95, 2362-2380 (2012).

38. Cook, N. B., Mentink, R. L., Bennett, T. B. \& Burgi, K. The effect of heat stress and lameness on time budgets of lactating dairy cows. J. Dairy Sci. 90, 1674-1682 (2007).

39. do Amaral, B. C. et al. Heat stress abatement during the dry period influences metabolic gene expression and improves immune status in the transition period of dairy cows. J. Dairy Sci. 94, 86-96 (2011).

40. Adriaens, I. et al. Method for short-term prediction of milk yield at the quarter level to improve udder health monitoring. $J$. Dairy Sci. 101, (2018).

41. Abdelkrim, A. B., Puillet, L., Gomes, P. \& Martin, O. Lactation curve model with explicit representation of perturbations as a phenotyping tool for dairy livestock precision farming. Animal 15, (2021).

42. Poppe, M., Veerkamp, R. F., van Pelt, M. L. \& Mulder, H. A. Exploration of variance, autocorrelation, and skewness of deviations from lactation curves as resilience indicators for breeding. J. Dairy Sci. 103, (2020).

43. Mohr, E., Langbein, J. \& Nürnberg, G. Heart rate variability: A noninvasive approach to measure stress in calves and cows. Physiol. Behav. 75, (2002).

44. Peric, T. et al. Short communication: Hair cortisol concentrations in Holstein-Friesian and crossbreed F1 heifers. J. Dairy Sci. 96, (2013).

45. JENSEN, A. L., PETERSEN, M. B. \& HOUE, H. Determination of the Fructosamine Concentration in Bovine Serum Samples. J. Vet. Med. Ser. A 40, (1993).

46. Armbruster, D. A. Fructosamine: structure, analysis, and clinical usefulness. Clinical chemistry vol. 33 (1987).

47. Caré, S. et al. Plasma fructosamine during the transition period and its relationship with energy metabolism and inflammation biomarkers in dairy cows. Livest. Sci. 216, (2018).

48. Welfare Quality, 2009. Welfare Quality® assessment protocol for cattle.Welfare Quality ${ }^{\circledR}$ Consortium, Lelystad, Netherlands

\section{Figures}

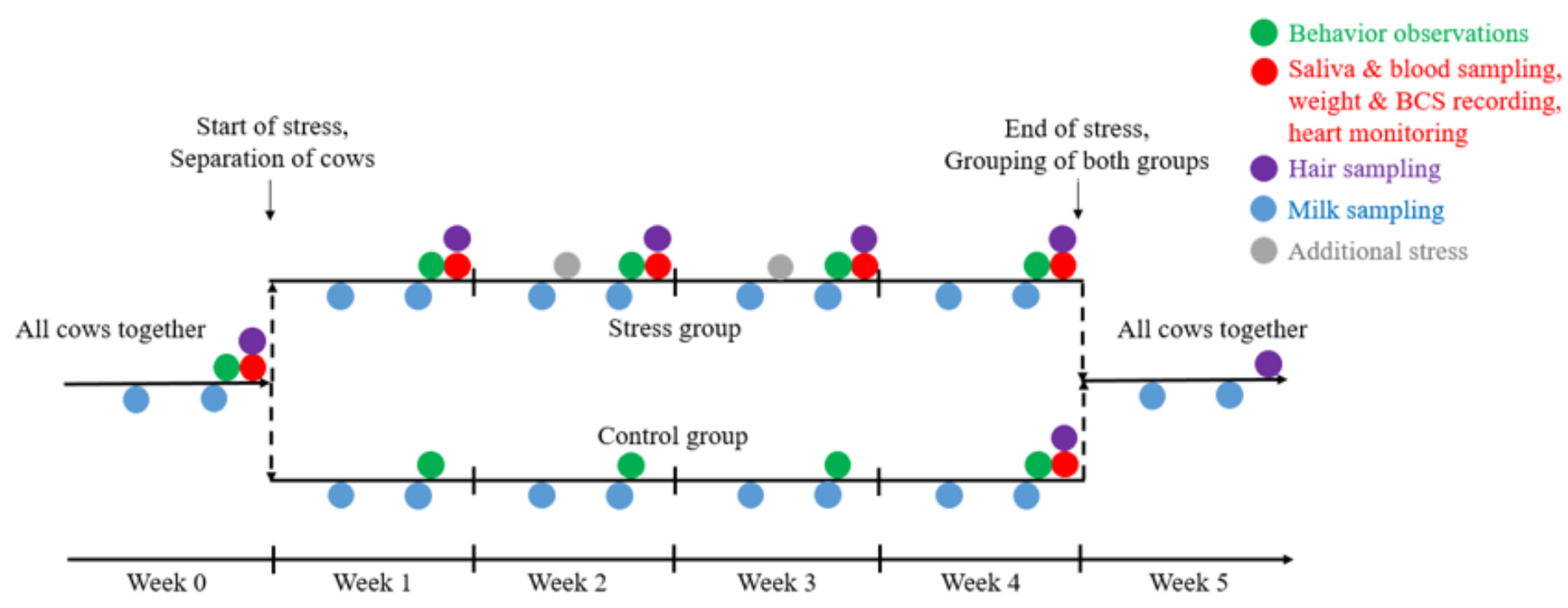

Figure 1

Page 20/22 
Schematic representation of groups handling following weeks of the experiment. Stress started in week 1 and finished at the end of week 4. Monitoring and sampling times in the different weeks, for both groups, are also represented.

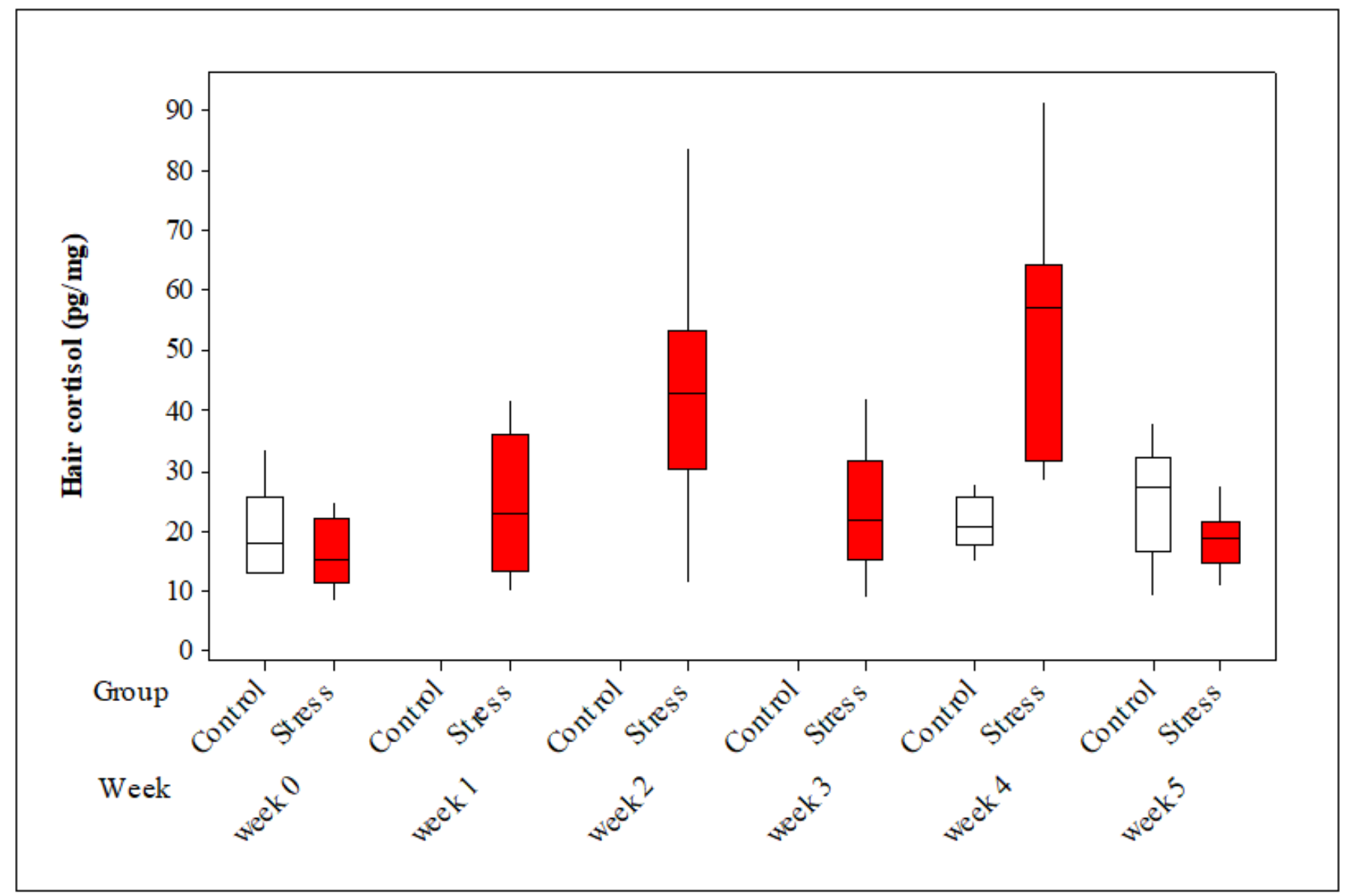

\section{Figure 2}

Boxplot of hair cortisol distribution following weeks and groups. Stress was induced from week 1 to 4 through severe overstocking, restricted access to feed and punctual unusual events. Hairs collected in week 0 were $2 \mathrm{~cm}$ long, which correspond approximately to 40 days of hair growth. Hairs collected on the stress group in weeks 1 to 5 and hairs collected in the control group in week 5 were corresponding to one week growth, whereas control group was not sampled in weeks 1 to 3 to avoid induction of stress and hairs collected in week 4 were corresponding to 4 weeks growth. 


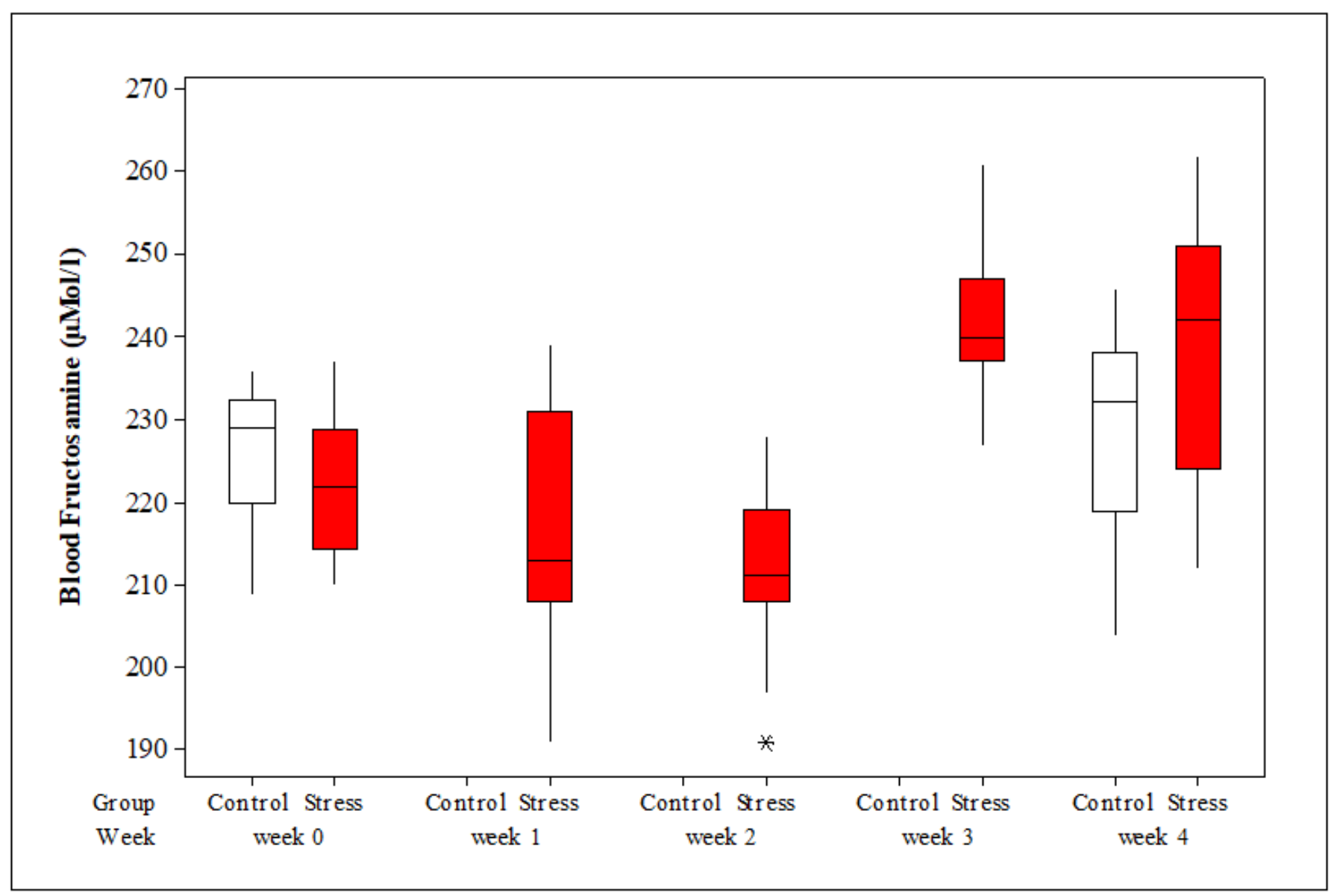

Figure 3

Boxplot of blood fructosamine distribution following weeks and groups. Stress was induced from week 1 to 4 through severe overstocking, restricted access to feed and punctual unusual events.

\section{Supplementary Files}

This is a list of supplementary files associated with this preprint. Click to download.

- Supplementarytable.docx 